\title{
STUDIES ON THE MECHANISM OF OXYGEN-INDUCED HYPOVENTILATION. AN EXPERIMENTAL APPROACH.*
}

\author{
By THOMAS B. BARNETT AND RICHARD M. PETERS
}

(From the Departments of Medicine and Surgery, University of North Carolina, School of Medicine, Chapel Hill, N. C.)

(Submitted for publication June 8, 1961 ; accepted October 19, 1961)

Increase in arterial blood carbon dioxide tension and hydrogen ion concentration is associated with a prompt increase in alveolar ventilation. Hypoxia of moderate degree has no appreciable effect on ventilation under normal circumstances nor does the administration of oxygen to the normal subject result in a decrease in ventilation. This may not be true, however, in certain disease states. Beddard and Pembrey (2), in 1908, noted a decrease in ventilation when patients with chronic pulmonary disease were allowed to breathe oxygen. In 1931, Barach and Richards (3) made similar observations in a patient with pulmonary insufficiency. The decreased ventilation in their case was accompanied by a marked rise in arterial $\mathrm{PCO}_{2}$. It was not until much later that it became generally recognized that the hypoventilation associated with the administration of oxygen to patients with pulmonary emphysema may result in serious respiratory acidosis, coma, and even death $(4,5)$. The mechanisms responsible for the hypoventilation accompanying oxygen administration remain obscure. Since patients with emphysema are known to have a diminished ventilatory response to increased concentration of carbon dioxide in the inspired air $(6,7)$, the most attractive hypothesis regarding the mechanism of oxygen-induced hypoventilation has been that hypoxia takes on a more important role in the over-all ventilatory drive when the response to the $\mathrm{CO}_{2}-\mathrm{pH}$ stimulus is no longer normal. Under these circumstances, the administration of oxygen eliminates the hypoxic stimulus, thus leading to hypoventilation.

The relative importance of adaptive mechanisms (acclimatization) and mechanical factors

* An abstract covering part of this investigation was published in January, 1960 (1). Supported in part by U. S. Public Health Service Grant H-1257, and in part by the Wright Air Development Division, Wright-Patterson Air Force Base, Ohio. (increased work of breathing) in the altered ventilatory response to carbon dioxide in patients with emphysema remains a controversial subject (8). Little is known about the influence of these two factors on the phenomenon of oxygen-induced hypoventilation.

The present paper describes the reproduction of the phenomenon of oxygen-induced hypoventilation in dogs with permanent tracheostomies and increased external respiratory dead space. These dogs exhibit certain important features of pulmonary insufficiency and are uniquely suited to studies designed to separate the effects of increased respiratory work from other factors, since the former can be altered at will.

\section{METHODS}

All experiments were carried out without anesthesia in trained dogs with permanent tracheostomies. A detailed description of this animal preparation has been reported elsewhere (9). The respiratory dead space was increased by adding to the airway a length of vinyl plastic tubing $(3 / 4$ inch ID) sufficient to increase the dead space by 250 to $300 \mathrm{cc}$ or approximately $15 \mathrm{cc}$ per $\mathrm{kg}$. This volume of dead space has been found to be well tolerated and to lead to significant elevation of arterial carbon dioxide tension in most instances when maintained for more than 48 hours (9). All experiments were done in the same quiet room in which the temperature was maintained between $19^{\circ}$ and $21^{\circ} \mathrm{C}$. The same dog attendant was used in all experiments.

Arterial blood samples were collected anaerobically in heparinized syringes from an indwelling needle in the femoral artery. Duplicate determinations were made of whole blood $\mathrm{pH}$ using a Beckman model GS $\mathrm{pH}$ meter and were corrected to body temperature by adding $0.0147 \mathrm{pH}$ unit for each degree of temperature difference. Plasma carbon dioxide content was measured with the Van Slyke manometric apparatus. Arterial carbon dioxide tensions were calculated by means of the HendersonHasselbalch equation. Arterial oxygen content and capacity were determined in duplicate by the spectrophotometric method of Hickam and Frayser (10). A twoway set of fish-mouth valves attached to the airway allowed for collection of expired air in a $350 \mathrm{~L}$ chaincompensated Tissot spirometer with recording kymograph. 
Respiratory rate and minute volume were determined from the kymograph tracing. Either room air or one of the experimental gas mixtures was introduced through the inspiratory side arm of the valve. Estimates of total dead space were based on the observed physiologic dead space in dogs with added dead space, reported elsewhere (9). Minute alveolar ventilation ( $\left.V_{A}\right)$ was then calculated from the formula $V_{A}=\left(V_{T}-V_{D S}\right) f$, where $\mathrm{VT}$ is tidal volume; VDS estimated total dead space, and $f$ respiratory rate per minute. All volumes were converted to conditions of saturated gas at body temperature and ambient pressure.

Administration of oxygen. Thirty minutes after the arterial needle was inserted, during which time the dog was breathing room air, respiratory rate, minute ventilation, and arterial $\mathrm{PCO}_{2}$ and oxygen saturation were measured. These observations were repeated after $30 \mathrm{~min}$ utes of breathing 50 per cent oxygen in nitrogen. Fifty per cent oxygen was used rather than 100 per cent oxygen, since the latter may have a stimulating effect on ventilation. Indeed in some earlier experiments, use of 100 per cent oxygen in dogs was associated with considerable evidence of restlessness and at times hyperventilation. Nine such control studies were done in 7 animals. After these observations, the dead space tubing was added and allowed to remain in place for 3 days. The above measurements were repeated with the dead space attached, first while the dog breathed room air and again after a 30 -minute period of breathing 50 per cent oxygen. A total of 14 experiments of this type was done in the 7 dogs. In most of the latter instances ventilation was measured 5 minutes after room air was again introduced by turning a valve on the inspiratory side of the system.

Ventilatory response to carbon dioxide. Six additional experiments were carried out with 3 of the same dogs that were used in the oxygen studies. These experiments were designed to test the ventilatory response to carbon dioxide in dogs before, during, and after the addition of dead space to the airway. A 3-minute period of ventilation was measured and $\mathrm{PCO}_{2}$ determined after at least 30 minutes of breathing room air and after 10 minutes of breathing one or two concentrations of carbon dioxide. The dogs breathed room air for at least 15 minutes between the two periods of carbon dioxide breathing, when two different levels were used. This sequence was repeated within a period of 30 to 45 minutes after adding $15 \mathrm{cc}$ of dead space per $\mathrm{kg}$, again after the extra dead space had been maintained for 3 days, and again 30 to 45 minutes after removing the dead space. The gas mixtures contained 3 and 5 per cent carbon dioxide in those studies with added dead space and 4 and 6 per cent carbon dioxide in those without dead space, in order to maintain approximately comparable levels of arterial $\mathrm{PCO}_{2}$. The two different concentrations were used except in two experiments in which the carbon dioxide response study was done at the same time as the oxygen breathing study. In these instances, only one concentration of
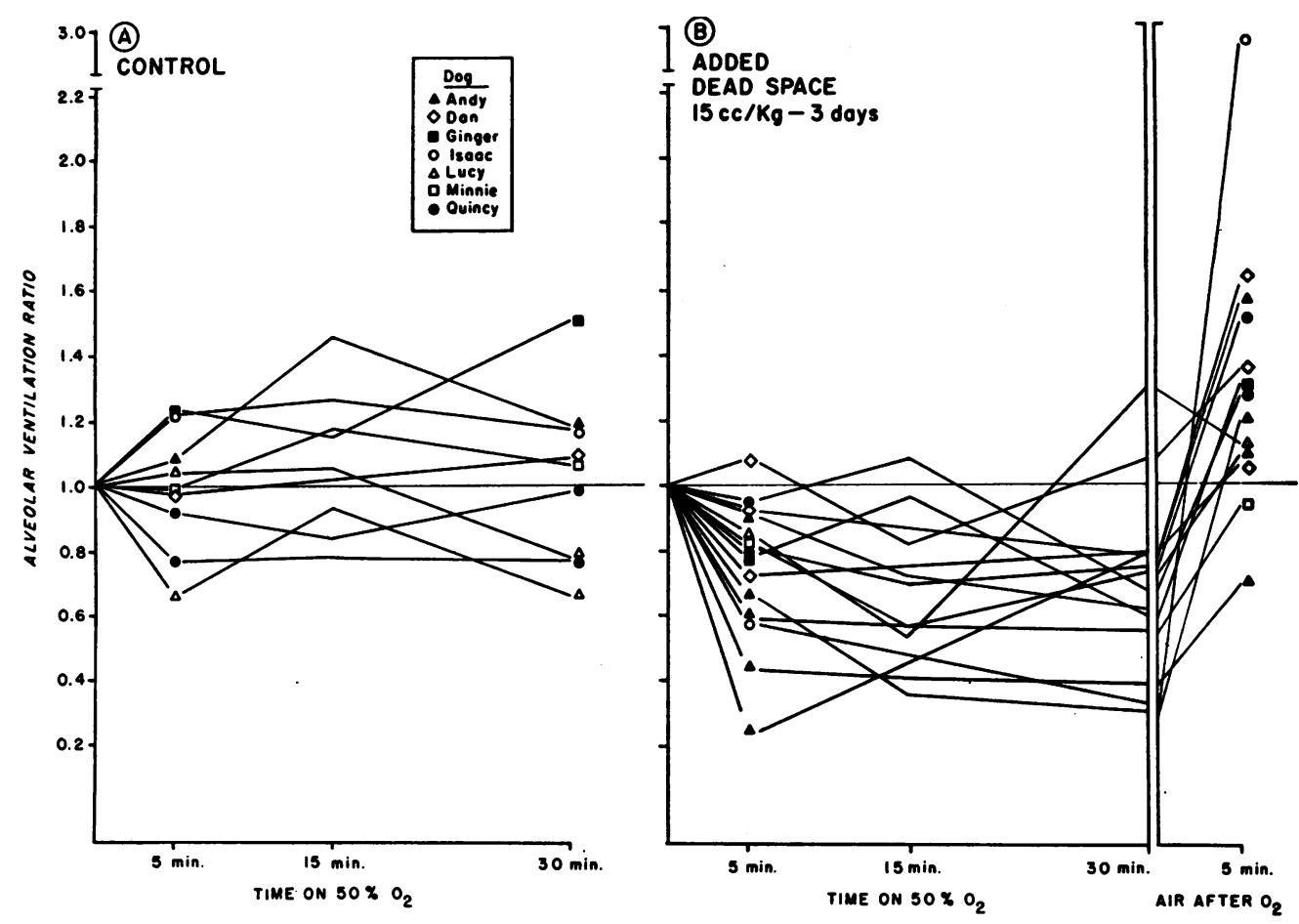

Fig. 1. Alveolar ventilation ratio in dogs breathing 50 per cent oxygen without added DEAD SPACE (A) AND AFTER 3 DAYS WITH ADDED DEAD SPACE (B). In graph B the ventilation ratio 5 minutes after discontinuing oxygen is shown. 
carbon dioxide ( 5 or 6 per cent) was tested in an effort to avoid prolongation of the experiment and excessive removal of blood. All gas mixtures contained, in addition to carbon dioxide, approximately 25 per cent oxygen, the remainder being composed of nitrogen.

\section{RESULTS}

Effects of breathing 50 per cent oxygen. Figure 1 shows the change in alveolar ventilation in dogs with and without added dead space at 5,15 , and 30 minutes after starting 50 per cent oxygen breathing. These values are expressed as the ratio of the observed ventilation with oxygen to the initial level of ventilation with air. The mean value for alveolar ventilation with air was not significantly different with added dead space $(2.0$ $\mathrm{L}$ per minute) from that in the controls $(1.9 \mathrm{~L}$ per minute). In the control studies (Figure 1A) the ventilatory response to oxygen was variable. In four instances the net effect was one of slight to moderate increase in ventilation during the 30minute period, in three instances the alveolar ventilation was slightly lower during the entire period of oxygen breathing, and in two cases there was no change in alveolar ventilation. After 3 days with added respiratory dead space (Figure $1 \mathrm{~B})$, the breathing of 50 per cent oxygen was, with few exceptions, associated with a prompt fall in alveolar ventilation-at times to less than half the original level. After this initial fall, the ventilation tended to remain at a low level. It will be noted in Figure 1B that alveolar ventilation rose sharply when dogs with added dead space were turned back to room air after 30 minutes of breathing oxygen. The one exception was in a dog that showed an unusual rise in ventilation during the latter half of the period of oxygen breathing.

For purposes of statistical analysis, an estimated total relative alveolar ventilation for the oxygen breathing period was determined in the following manner. Estimates of the total alveolar ventilation for each time interval (i.e., 5 minutes, 5 to 15 minutes, 15 to 30 minutes) were based on an average of the ventilation at the beginning and end of each interval. This estimated total ventilation for the interval was then expressed as a ratio of the ventilation with air. The sum of these ratios was used as the estimated total relative alveolar ventilation for the entire 30 -minute period of oxygen breathing. When more than one study

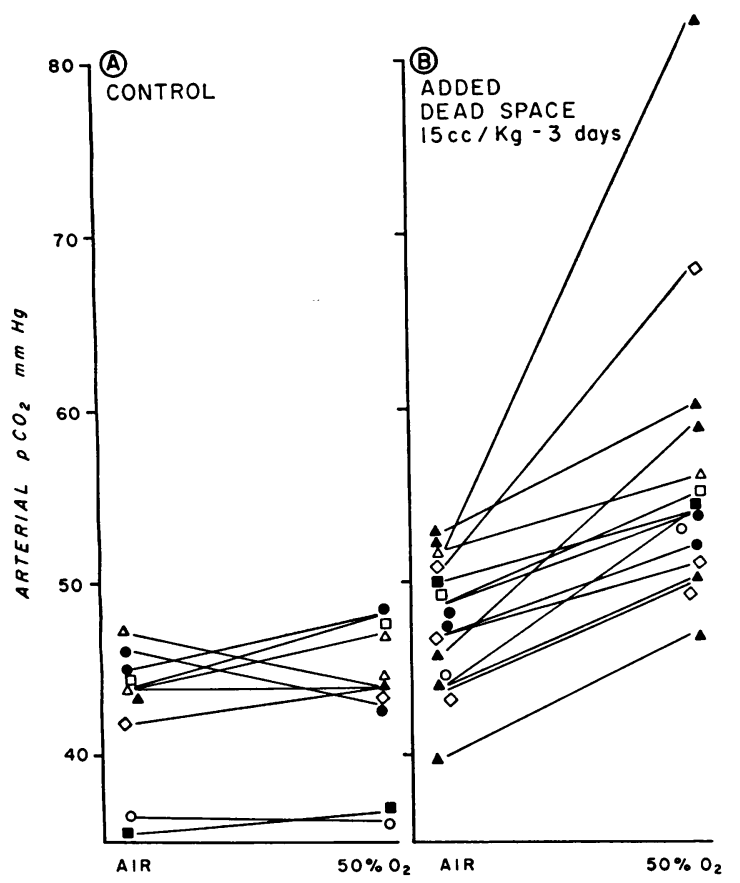

Fig. 2. EFFECT OF OXYGEN BREATHING ON ARTERIAL $\mathrm{P}_{\mathrm{CO}_{2}}$ Without Added DeAd SPACE (A), ANd With AdDEd DEAD SPACE (B). The same symbols are used as in Figure 1 .

was done on any dog, an average figure was used. Mean differences were calculated for control vs added dead space studies and their significance tested by the $t$ test. The difference in response to 50 per cent oxygen was found to be highly significant $(\mathrm{p}=<0.01)$.

Figure 2 shows the values for arterial $\mathrm{PCO}_{2}$ with the dog breathing room air, and after 30 minutes of breathing 50 per cent oxygen in controls (Figure 2A), and in dogs after 3 days with added dead space (Figure 2B). In the control dogs there was a slight rise in $\mathrm{PcO}_{2}$ in five instances, a slight fall in three, and no change in one. In those dogs with added dead space, oxygen breathing was invariably associated with a rise in arterial $\mathrm{PCO}_{2}$, and in many instances this in-

TABLE I

Effect of oxygen breathing on arterial $\mathrm{PCO}_{2}$ in dogs with and without added dead space *

\begin{tabular}{lcc}
\hline \hline & Air & $\mathrm{O}_{2}(30 \mathrm{~min})$ \\
\hline & $m m \mathrm{Hg}$ & $m m \mathrm{Hg}$ \\
Control & $41.38 \pm 1.54$ & $42.62 \pm 1.58$ \\
Added VDS & $48.12 \pm 0.93$ & $54.84 \pm 1.13$ \\
\hline
\end{tabular}

* Means \pm standard error of mean. 
TABLE II

Arterial oxygen 'saturation and $P_{\mathrm{CO}_{2}}$ before and after 30 minutes of breathing 50 per cent oxygen in dogs with added dead space

\begin{tabular}{|c|c|c|c|c|}
\hline \multirow[b]{2}{*}{ Dog } & \multicolumn{2}{|c|}{$\begin{array}{l}\text { Arterial } \mathrm{O}_{2} \\
\text { saturation }\end{array}$} & \multicolumn{2}{|c|}{ Arterial Pco2 } \\
\hline & Air & $50 \% \mathrm{O}_{2}$ & Air & $50 \% \mathrm{O}_{2}$ \\
\hline A & $\begin{array}{l}\% \\
93 \\
92 \\
95 \\
93 \\
93\end{array}$ & $\begin{array}{r}\% \\
98 \\
98 \\
100 \\
99 \\
100\end{array}$ & $\begin{array}{c}m m \mathrm{Hg} \\
46 \\
52 \\
53 \\
44 \\
40\end{array}$ & $\begin{array}{c}m m \mathrm{Hg} \\
59 \\
82 \\
60 \\
50 \\
47\end{array}$ \\
\hline $\mathrm{D}$ & $\begin{array}{l}95 \\
90 \\
93\end{array}$ & $\begin{array}{l}100 \\
100 \\
100\end{array}$ & $\begin{array}{l}47 \\
51 \\
44\end{array}$ & $\begin{array}{l}51 \\
68 \\
50\end{array}$ \\
\hline $\begin{array}{l}\mathrm{G} \\
\mathrm{I} \\
\mathrm{L} \\
\mathrm{M} \\
\mathrm{Q}\end{array}$ & $\begin{array}{l}95 \\
95 \\
96 \\
93 \\
95\end{array}$ & $\begin{array}{r}98 \\
96 \\
\\
100 \\
99 \\
100\end{array}$ & $\begin{array}{l}50 \\
44 \\
52 \\
49 \\
49 \\
47\end{array}$ & $\begin{array}{l}54 \\
54 \\
56 \\
55 \\
54 \\
52\end{array}$ \\
\hline
\end{tabular}

crease was to quite high levels. In one dog, the arterial $\mathrm{PCO}_{2}$ rose from 52 to $82 \mathrm{~mm} \mathrm{Hg}$ while alveolar ventilation decreased from 1.91 to 0.58 $\mathrm{L}$ per minute. Not shown in Figure 2B were the

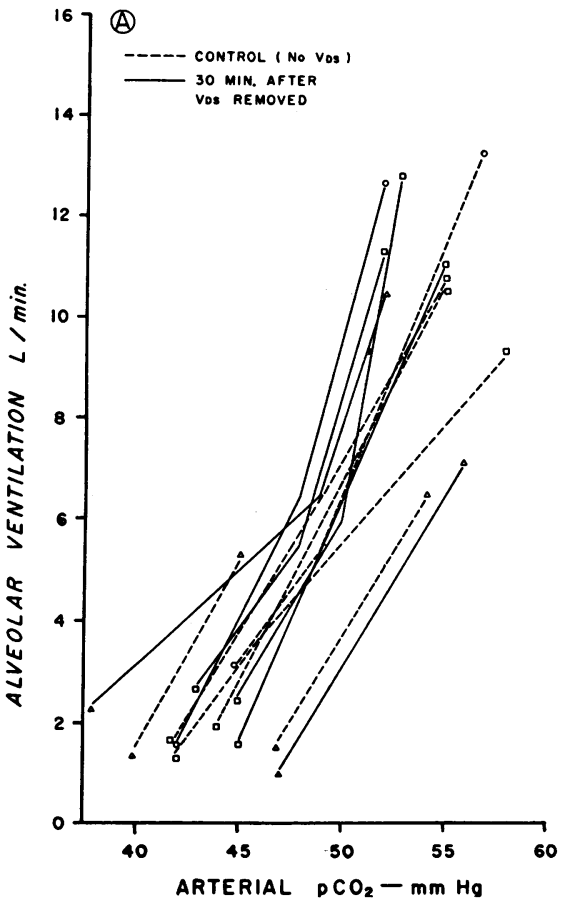

three instances in which $\mathrm{PCO}_{2}$ values were determined 10 minutes after oxygen was discontinued. In all instances these had returned to the original levels.

The means and standard errors for the arterial $\mathrm{PCO}_{2}$ determinations with air and with oxygen, with and without added dead space, are shown in Table I. Paired $t$ tests show that in dogs without added dead space the difference between the mean values with oxygen are not significantly different from those with air. In those dogs with added dead space, however, there was a significant increase in arterial $\mathrm{PCO}_{2}$ with 30 minutes of oxygen breathing $(\mathrm{p}=<0.05)$. Although the mean arterial $\mathrm{PCO}_{2}$ values for dogs with added dead space breathing room air were significantly higher than in the controls, there was not a clear relationship between the level of arterial $\mathrm{PCO}_{2}$ during air breathing and the degree of change during oxygen breathing (see Figure 2). It will be noted that in the two instances of most marked change in $\mathrm{PCO}_{2}$, however, the initial levels were above 50 $\mathrm{mm} \mathrm{Hg}$. On the other hand, two other dogs with equally high initial $\mathrm{CO}_{2}$ tension showed only

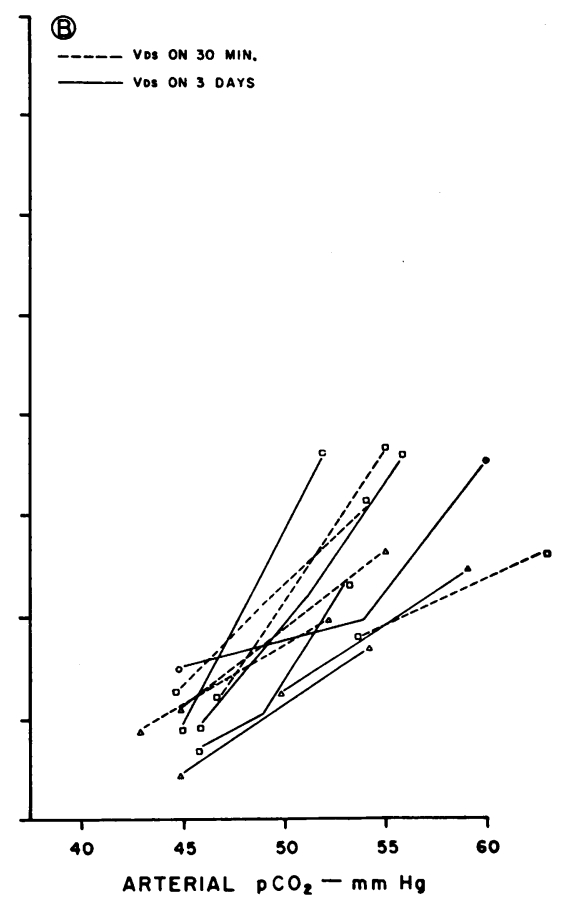

Fig. 3. VENTILATORY RESPONSE TO CARBON DIOXIDE EXPRESSED IN TERMS OF ALVEOLAR VENTILATION IN DOGS WITHOUT ADDED DEAD SPACE (A) AND WITH ADDED DEAD SPACE (B). In both graphs the dotted lines represent initial studies; the solid lines represent studies done at the end of 3 days with added dead space. Dog symbols correspond to those shown in Figure 1. 

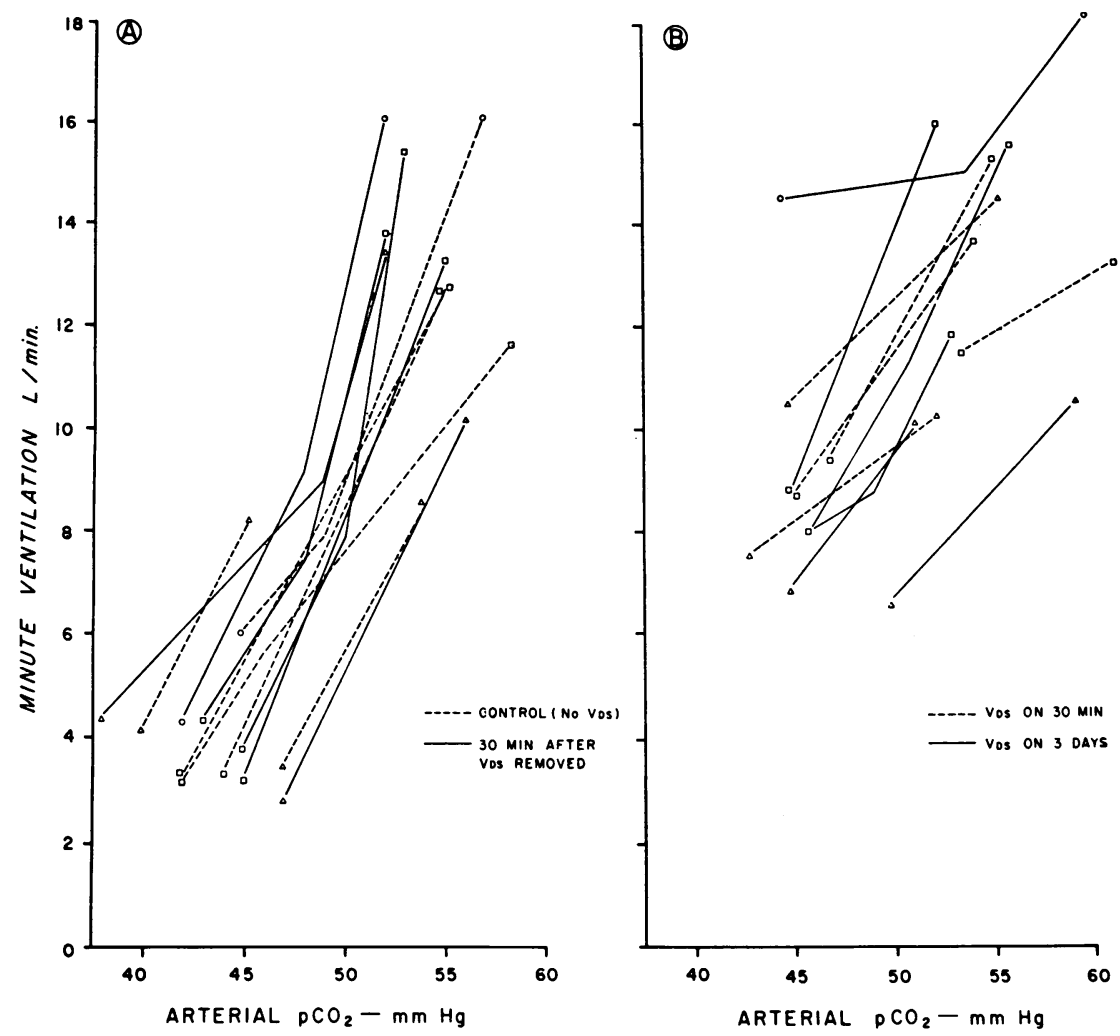

Fig. 4. Ventilatory RESPONSE TO CARBON DIOXIDE EXPRESSED IN TERMS OF MINUTE VENTILATION IN DOGS WITHOUT ADDED DEAD SPACE (A) AND WITH ADDED DEAD SPACE (B). The line and symbol designations are the same as in Figure 3.

moderate increase with oxygen, and, in two other instances, quite marked increase in arterial $\mathrm{PCO}_{2}$ occurred when the initial $\mathrm{PcO}_{2}$ was within normal limits.

Table II shows the $\mathrm{PCO}_{2}$ and oxygen saturation of arterial blood in dogs with added dead space that breathed room air and 50 per cent oxygen. The most marked rise in $\mathrm{PCO}_{2}$ occurred in three instances in which the initial oxygen saturations were well below normal. Oxygen saturations were normal (95 per cent or more) in six instances, however, in which moderate increase in $\mathrm{PCO}_{2}$ occurred with oxygen breathing.

Ventilatory response to carbon dioxide. The ventilatory response to carbon dioxide in dogs without added dead space is shown in Figure 3A. Here the response is depicted in terms of alveolar ventilation and, although the mean slope and position of the curves before dead space was added (dotted lines) are not significantly different from those shortly after removal of dead space (solid lines), the former tended to be slightly to the left of and slightly steeper than the latter. In Figure 3B the alveolar ventilation with added dead space is plotted against arterial $\mathrm{PCO}_{2}$. These response lines are shifted to the right and are less steep than those in Figure 3A. Although these lines show a wider scatter, there is again no apparent difference when one compares the response immediately after adding dead space (dotted lines) with that after 3 days with added dead space (solid lines). While the difference between the mean slopes was not significant, the response after 3 days of added dead space tended to be slightly greater than that observed immediately after adding dead space. To use the commonly employed terminology then, the "sensitivity" and "threshold" of the ventilatory response are both altered by adding dead space when this response is expressed in terms of alveolar ventilation, but further change does not occur with time ( 3 days), and on removal of the extra dead space the ventilatory response returns promptly to normal. 
In Figure 4 the ventilatory response is expressed in terms of minute ventilation. This measurement can be assumed to reflect more closely the total effort of breathing than does alveolar ventilation in these dogs. It will be noted that the response with added dead space corresponds more closely to that in the controls. The slope of some of the lines, however, remains flattened. As was the case with the alveolar ventilation response, there was no real difference in the position or slope of the lines before and after the 3-day period of added dead space.

\section{DISCUSSION}

The use of trained experimental animals in studies of this type not only carries a risk of erroneous conclusions due to species differences, but the avoidance of anesthesia and sedation undoubtedly allows for the introduction of other variables that are difficult to control just as in studies on trained human subjects. The artificial addition of dead space to the airway does not reproduce all of the functional abnormalities of any naturally occurring disease of the lung. Recognizing these limitations to an experimental approach of this type, and realizing that care must be taken in the interpretation of results, there are nevertheless many advantages to the use of this experimental model. These animals clearly require greater than normal effort for any given volume of alveolar ventilation and, as indicated by retention of carbon dioxide, they develop a state of alveolar hypoventilation. In these as well as in previous studies of the effects of added respiratory dead space in unanesthetized dogs (9), it was noted that added dead space was not associated with a decrease in alveolar ventilation. The increase in arterial $\mathrm{PCO}_{2}$ in these dogs must therefore be attributed to a relative alveolar hypoventilation in animals with an increase in the work of breathing. Presumably a comparable increase in nonrespiratory work would have been accompanied by an increase in alveolar ventilation. To the extent that hypoventilation occurs in association with increased respiratory work, such clinical states as pulmonary emphysema, severe obesity, and kyphoscoliotic pulmonary disease are simulated.

While several theories have been offered to explain the phenomenon of oxygen-induced hypoventilation seen in various disease states, it has not been possible to define any one circumstance or any combination of circumstances clearly necessary for the occurrence of this phenomenon. In patients with chronic hypoxia due to conditions other than pulmonary disease, the administration of oxygen does not lead to hypoventilation (11). In studying patients with emphysema, Richards, Fritts and Davis (12) found that in one group there was significant carbon dioxide retention at rest, whereas in the other, the arterial $\mathrm{PCO}_{2}$ was normal or only slightly elevated. Breathing 50 per cent oxygen was associated with a decrease in ventilation in the hypercapneic patients, but not in those who had a more nearly normal initial arterial $\mathrm{PCO}_{2}$. This was true even though the arterial blood oxygen saturations were comparable in the two groups. Brodovsky, Macdonnell and Cherniack (13), on the other hand, found that the administration of 100 per cent oxygen to patients with emphysema led to hypercapnia even in patients who were normocapneic at rest while they breathed room air. In studies on 12 patients with pulmonary emphysema, Wood and Barnett (14) observed a fall in ventilation in two instances, both with 50 per cent oxygen and with 100 per cent oxygen when the resting arterial $\mathrm{PCO}_{2}$ was normal. Oxygen breathing resulted in hypoventilation in only one case in which the initial oxygen saturation was normal. In the present studies the three instances in which, with oxygen breathing, the greatest rise in $\mathrm{PCO}_{2}$ occurred, the initial oxygen saturations were distinctly subnormal, i.e., 93, 92, and 90 per cent. Although some degree of hypoventilation occurred in several instances when the initial oxygen saturation was near normal (95 to 96 per cent), in this range a slight change in oxygen saturation is associated with a relatively large change in oxygen tension. Therefore some degree of hypoxia may have been present in our dogs as well as in the subjects studied by Richards and co-workers (12). As in the experience of Brodovsky and associates (13), we found hypercapnia developing during oxygen breathing in four instances in which the $\mathrm{PCO}_{2}$ during air breathing was $45 \mathrm{~mm}$ $\mathrm{Hg}$ or less.

Although these findings suggest that neither marked hypercapnia or hypoxia is essential to 
the development of oxygen-induced hypoventilation, they in no way indicate that these factors, when present, play no role in this phenomenon.

It has been assumed by most observers that some decrease in the ventilatory response to carbon dioxide must be present when oxygen-induced hypoventilation occurs. With only one exception, the arterial $\mathrm{PCO}_{2}$ in dogs with added dead space rose to $50 \mathrm{~mm} \mathrm{Hg}$ or higher after oxygen breathing (Table II). Alveolar ventilation was invariably low, usually below $2.0 \mathrm{~L}$ per minute, and in many instances below $1.0 \mathrm{~L}$ per minute. When one considers the normal ventilatory response to hypercapnia of this degree (Figure 3A), it is difficult to escape the conclusion that the ventilatory response to carbon dioxide is abnormal in these dogs with added dead space.

Aside from factors such as drugs, which clearly act on the central respiratory centers, there are two situations that are known to alter the ventilatory response to carbon dioxide-namely, prolonged exposure to high atmospheric carbon dioxide, and an increase in the work of breathing. Schäfer (15) exposed human subjects to 3 per cent carbon dioxide for periods of from 3 to 6 days and found that the ventilatory response to carbon dioxide was diminished thereafter. In similar studies, Chapin, Otis and Rahn (16) found that after 13 hours in an atmosphere containing 3 per cent carbon dioxide the ventilatory response to carbon dioxide was reduced. This acclimatization to carbon dioxide was found to have been lost within 20 hours after the subjects returned to room air. The fact that the acclimatization to hypercapnia, like acclimatization to hypocapnia, is a time-dependent phenomenon, is most pertinent to the interpretation of the results of the present study.

The other circumstance that has been shown to reduce the ventilatory response to carbon dioxide is an increase in the work of breathing accomplished by artificially increasing airway resistance. Cherniack and Snidal (17) and Eldridge and Davis (18) have demonstrated that artificial introduction of airway obstruction in normal human subjects results in an abnormal ventilatory response to carbon dioxide comparable to that seen in pulmonary emphysema. That the abnormal ventilatory response to carbon dioxide in patients with emphysema is related, at least in part, to the increase in the work of breathing has been demonstrated repeatedly. Richards and co-workers (12) and more recently Brodovsky and associates (13) showed that patients with emphysema differed little from normal subjects when ventilatory response to carbon dioxide was measured in terms of the oxygen cost of breathing, even though the resulting ventilation was lower in the emphysematous patients.

We have demonstrated that by adding dead space to the airway (15 cc per $\mathrm{kg}$ for 3 days) dogs show a fall in ventilation and a rise in arterial $\mathrm{PCO}_{2}$ when allowed to breathe 50 per cent oxygen for 30 minutes. Assuming that this situation may be related to an alteration in the ventilatory response to carbon dioxide, we have measured this response before, during, and after a 3-day period with the same amount of added dead space. In two instances the effects of oxygen breathing and the carbon dioxide response studies were done concomitantly. Added dead space did not alter the ventilatory response to carbon dioxide when this response was expressed in terms of total ventilation (Figure 4). In this animal preparation, total ventilation would seem to be a more accurate indicator of the response to carbon dioxide than would the alveolar ventilation. Total ventilation more nearly reflects the total breathing effort in these dogs just as does a measurement of respiratory work in patients with emphysema. An apparent decrease in ventilatory response was, however, observed when arterial $\mathrm{PCO}_{2}$ was plotted against alveolar ventilation (Figure 3). This change in response occurred immediately after dead space was added, did not change further when measured 3 days later, and returned promptly to control levels immediately after removal of the dead space. In fact, when there was a difference in the response before and after 3 days of added respiratory work, the line representing the response after removal of the dead space was, more often than not, to the left of the control line. In other words, under circumstances identical with those shown to result in oxygen-induced hypoventilation, it was not possible to demonstrate any evidence of acclimatization to carbon dioxide.

It would appear then that an alteration in the sensitivity to carbon dioxide as a respiratory stimulus, other than that attributable to increase in 
the work of breathing, is not essential to the occurrence of hypoventilation on breathing oxygen. It cannot be concluded, however, that factors other than increased work of breathing play no role in this phenomenon. From clinical experience it is clear that sedative and narcotic drugs often contribute to the development of hypoventilation when oxygen is administered to patients with emphysema. The fact that it was not possible in our studies to demonstrate acclimatization to carbon dioxide in a situation in which oxygeninduced hypoventilation occurred in no sense precludes the possibility that acclimatization may under certain circumstances contribute to the development of oxygen-induced hypoventilation. It remains to be determined whether or not acclimatization to high environmental carbon dioxide is associated with an abnormal response to oxygen breathing in the absence of increased respiratory work.

Bannister and Cunningham (19) found that the administration of oxygen during exercise carried to the point of exhaustion reduced ventilation and raised the $\mathrm{PCO}_{2}$. Much less total effort expended on respiratory work may lead to exhaustion in the animals reported here and in patients with pulmonary emphysema. It seems possible that an increase in respiratory work alone, if of sufficient magnitude, may be the principal factor responsible for the relative hypoventilation associated with the administration of oxygen. When the work of breathing is increased, not only is there a greater production of carbon dioxide, but the effective ventilation associated with a rise in arterial $\mathrm{PCO}_{2}$ is also less than normal. Lloyd, Jukes and Cunningham (20) have shown that, in the presence of decreased alveolar oxygen tension, there is a relatively greater rise in ventilation from a given rise in arterial $\mathrm{PcO}_{2}$. When the work of breathing is increased, even very slight hypoxia may, therefore, be of considerable importance in maintaining adequate ventilation. The removal of this additional stimulus would be expected to result in decreased ventilation and increased respiratory acidosis.

It seems unlikely that any single factor will be found to account for all instances of oxygeninduced hypoventilation in view of the complex relationships involved in the regulation of respiration. The data reported here indicate that in- creased work of breathing is one of the important factors in the development of this phenomenon.

\section{SUMMARY}

1. Hypoventilation with accompanying hypercapnia has been observed when dogs with artificially increased respiratory dead space are allowed to breathe 50 per cent oxygen.

2. Decreased ventilation during oxygen breathing did not seem to depend solely on a state of hypoxia or of hypercapnia prior to the period of oxygen breathing.

3. The circumstances under which hypoventilation occurred with oxygen breathing-namely, 15 cc added dead space per $\mathrm{kg}$ for 3 days-were not associated with a decreased ventilatory response to carbon dioxide attributable to acclimatization; the only change in the response to carbon dioxide was that associated with an increase in the work required to ventilate the alveoli.

4. The importance of increased work of breathing as a factor in the regulation of ventilation has been discussed.

\section{ACKNOWLEDGMENT}

The authors acknowledge the helpful assistance of $\mathrm{Dr}$. H. Bradley Wells of the Department of Biostatistics, School of Public Health, University of North Carolina, in the statistical analysis of the results. Idalyn Spooner's technical assistance and other contributions to many aspects of this investigation are gratefully acknowledged.

\section{REFERENCES}

1. Barnett, T. B., and Peters, R. M. Oxygen induced hypoventilation in dogs with added dead space. Clin. Res. 1960, 8, 90.

2. Beddard, A. P., and Pembrey, M. S. Observations on pulmonary ventilation in disease. Brit. med. J. 1908, 2, 580.

3. Barach, A. L., and Richards, D. W., Jr. Effects of treatment with oxygen in cardiac failure. Arch. intern. Med. 1931, 48, 325.

4. Davis, C. E., and Mackinnon, J. Neurological effects of oxygen in chronic cor pulmonale. Lancet 1949, 2, 883.

5. Comroe, J. H., Jr., Bahnson, E. R., and Coates, E. O., Jr. Mental changes occurring in chronically anoxemic patients during oxygen therapy. J. Amer. med. Ass. 1950, 143, 1044.

6. Tenney, S. M. Ventilatory response to carbon dioxide in pulmonary emphysema. J. appl. Physiol. $1954,6,477$. 
7. Alexander, J. K., West, J. R., Wood, J. A., and Richards, D. W. Analysis of the respiratory response to carbon dioxide inhalation in varying clinical states of hypercapnia, anoxia, and acid-base derangement. J. clin. Invest. 1955, 34, 511.

8. Fritts, H. W., Jr. The energy cost and control of breathing in patients with chronic pulmonary emphysema. Amer. Rev. resp. Dis. 1959 (July, Part 2), 80, 131.

9. Barnett, T. B., and Peters, R. M. Unanesthetized dogs with increased respiratory dead space. J. appl. Physiol. 1960, 15, 838.

10. Hickam, J. B., and Frayser, R. Spectrophotometric determination of blood oxygen. J. biol. Chem. 1949, 180, 457.

11. Shephard, R. J. Respiratory responses to the inhalation of oxygen at atmospheric pressure in normal subjects and in cases of congenital heart disease. J. Physiol. (Lond.) 1955, 127, 498.

12. Richards, D. W., Fritts, H. W., Jr., and Davis, A. L. Observations on the control of respiration in emphysema: The effects of oxygen on ventilatory response to $\mathrm{CO}_{2}$ inhalation. Trans. Ass. Amer. Phycns 1958, 71, 142.

1. Brodovsky, D., Macdonnell, J. A., and Cherniack, R. M. The respiratory response to carbon dioxide in health and in emphysema. J. clin. Invest. 1960, 39, 724.

14. Wood, W. B., and Barnett, T. B. Unpublished data.

15. Schäfer, K. E. Atmung und Säure-Basengleichgewicht bei langdauerndem Aufenthalt in $3 \% \mathrm{CO}_{2}$. Pflüg. Arch. ges. Physiol. 1949, 251, 689.

16. Chapin, J. L., Otis, A. B., and Rahn, H. Changes in Sensitivity of the Respiratory Center in Man after Prolonged Exposure to $3 \% \mathrm{CO}_{2}$. Wright Air Development Center Technical Report 1955, p. 250.

17. Cherniack, R. M., and Snidal, D. P. The effect of obstruction to breathing on the ventilatory response to $\mathrm{CO}_{2}$. J. clin. Invest. 1956, 35, 1286.

18. Eldridge, F., and Davis, J. M. Effect of mechanical factors on respiratory work and ventilatory responses to $\mathrm{CO}_{2}$. J. appl. Physiol. 1959, 14, 721.

19. Bannister, R. G., and Cunningham, D. J. C. The effects on the respiration and performance during exercise of adding oxygen to the inspired air. J. Physiol. (Lond.) 1954, 125, 118.

20. Lloyd, B. B., Jukes, M. G. M., and Cunningham, D. J. C. The relation between alveolar oxygen pressure and the respiratory response to carbon dioxide in man. Quart. J. exp. Physiol. 1958, 43, 214. 